Acta Poetica 30-2

OTOÑO

2009

\title{
Walter Benjamin y la crítica literaria
}

\author{
Esther Cohen
}

En una carta a Gershom Scholem del 20 de enero de 1930, Walter Benjamin confesaba a su amigo de siempre: "el objetivo que me he propuesto no ha sido totalmente completado, pero estoy finalmente acercándome a él. El objetivo es ser considerado el mejor crítico de la literatura alemana. El problema es que la crítica literaria ya no es considerada como un género serio en Alemania [...] se debe recrear la crítica como un género". Ese género al que Benjamin alude, implicará, a lo largo de su obra, una relación directa con la filosofía y con el concepto de reflexión en su acepción tanto literaria como filosófica. Ya en su trabajo sobre el romanticismo alemán, el filósofocrítico explora este vínculo, de manera particular, en la obra de Schlegel. Si bien el pensamiento benjaminiano ha encontrado eco en filósofos y en teóricos del arte, la fotografía o el cine, su pretensión más íntima, la de convertirse en el mejor crítico literario de Alemania, ha quedado en la sombra. De eso trataremos aquí, de rescatar de las sombras ese deseo del pensador alemán.

Palabras clave: Walter Benjamin, crítica, romanticismo.

In a letter to Gershom Scholem of January 20, 1930, Walter Benjamin confessed to his ever friend: "the purpose I have proposed to myself has not been fully completed, but I am finally getting closer to it. The purpose is to be considered as the best critic of German literature. The problem is that literary criticism is no longer considered as a serious genre in Germany [...] criticism must be recreated as a genre". That genre alluded by Benjamin will imply, all over his work, a direct relationship with philosophy and with the concept of "reflection" in both literary and philosophical meaning. Early 
in his work on German Romanticism, the philosopher-critic explores this link, in a particular way, in the work of Schlegel. Even though benjaminian thought has founded echoes in philosophers and theoreticians of art, photography or film, his most intimate claim, that of becoming the best literary critic in Germany, has remained in the shadows. Here we will try to rescue from the shadows that desire of the German thinker.

KEY WORDS: Walter Benjamin, critics, romanticism.

Fecha de recepción: 12 de marzo de 2010

Fecha de aceptación: 10 de agsoto de 2010 


\section{Esther Cohen}

Instituto de Investigaciones Filológicas,

Universidad Nacional Autónoma de México

\section{Walter Benjamin y la crítica literaria}

Siempre radical, nunca consecuente.

Walter BenJAMin

Un hombre permanece vivo por el hecho de no estar aún concluido y de no haber dicho aún su última palabra.

MiJAíl BAJTín

Nuestra época es la época de la crítica, y hay que ver qué resultará de los intentos críticos de nuestro tiempo, especialmente en relación con la filosofía.

IMMANUEL KANT

Me horroriza la idea de triunfar en el mundo.

ROBERT WALSER

[...] la crítica es, sin duda, el guardián del umbral [...] es doblemente urgente devolver su poder a la palabra crítica en general. Pues, al contrario de lo que suele decirse, la crítica grande [no] tiene en absoluto que instruir a través de la exposición histórica, ni que formar con comparaciones, sino que está 
obligada a conocer sumergiéndose. La crítica grande tiene que dar razón de la verdad de las obras que el arte exige no menos que la filosofía (Benjamin, "Presentación de la revista 'Angelus Novus"”, 246. Énfasis mío).

"Guardián del umbral": ése es Benjamin quien, en su calidad de crítico literario y a la manera de su jorobadito oculto bajo el tablero, mueve los hilos de la historia, ${ }^{1}$ asumiéndose como celoso vigilante del lugar de la crítica asociada con el arte y la filosofía. Estos últimos, desde su perspectiva temprana, hallarán en su pensamiento un lugar común: la reflexión. A partir de su presentación a la revista Angelus Novus, escrita en 1921-1922 y que nunca llega a ver la luz, el pensador expone con gran lucidez lo que serán algunas de las coordenadas más importantes de su trabajo por venir. Desde la figura del umbral, ${ }^{2}$ hasta el

${ }^{1}$ Me refiero aquí a la primera Tesis sobre la historia (1940), donde Benjamin alude a uno de los temas recurrentes en toda su obra: la relación de la teología (jorobada y fea) con el materialismo histórico. Me permito citar in extenso la controvertida Tesis: "Según se cuenta, hubo un autómata construido de manera tal, que, a cada movimiento de un jugador de ajedrez, respondía con otro, que le aseguraba el triunfo en la partida. Un muñeco vestido de turco, con la boquilla de narguile en la boca, estaba sentado ante el tablero que descansaba sobre una amplia mesa. Un sistema de espejos producía la ilusión de que todos los lados de la mesa eran transparentes. En realidad, dentro de ella había un enano jorobado que era un maestro en ajedrez y que movía la mano del muñeco mediante cordeles. En la filosofía, uno puede imaginar un equivalente de ese mecanismo; está hecho para que venza siempre el muñeco que conocemos como 'materialismo histórico'. Puede competir sin más con cualquiera, siempre que ponga a su servicio a la teología, la misma que hoy, como se sabe, además de ser pequeña y fea, no debe dejarse ver por nadie" (Benjamin, Tesis sobre la historia y otros fragmentos, 17).

${ }^{2}$ Quiero aventurar que la figura del umbral puede ser de inspiración kafkiana. Sin embargo, me interesa subrayar que una expresión similar, "morador del umbral", corresponde al escritor inglés del siglo XIX, Edward George Bulwer Lytton, a quien Benjamin leyó y citó en dos de sus obras: "El París del Segundo Imperio en Baudelaire" (52) y el Libro de los pasajes. A pesar de esta similitud, no existe ninguna prueba segura que dé cuenta de esta 
acto de sumergirse en las obras como condición de todo conocimiento, Benjamin asume la "crítica" en términos que involucran al filósofo y al crítico. Ésa es la crítica grande a la que se refiere en su breve pero aguda presentación: toda crítica propiamente dicha debe considerarse como una epistemología, una teoría del conocimiento en busca de la verdad, fruto de la inmersión en la obra.

Pero, ¿qué significa para Benjamin ser guardián del umbral? Sabemos, por una carta de 1930, dirigida a su amigo Gershom Scholem, que su gran aspiración era convertirse en el mejor crítico de la literatura alemana. ${ }^{3}$ Si es así, Benjamin, percibido desde su espectro póstumo en las Tesis sobre la historia, no podía pretender menos que considerar tal concepto como el elemento fundador $\mathrm{y}$, en ese sentido, productivo y creativo, de todo conocimiento filosófico, artístico y literario. Recrear esta actividad como un género era justamente vincularla a la función epistemológica misma que ejerce el hacer filosófico; de ahí su temprano interés por el pensamiento romántico, en particular, por Friederich Schlegel y Novalis. En ellos encuentra Benjamin el primer impulso para desplegar su saber filosófico en términos de un romanticismo que se piensa y define a sí mismo, básicamente, como crítica, sea literaria o filosófica, sin distinciones ni jerarquías. De ahí que Benjamin se refiera a estos románticos, en su escrito sobre el romanticismo alemán, diciendo: "El pensamiento reflexivo adquirió para ellos, merced a su inacababilidad que hace de cada reflexión precedente objeto de la siguiente, una especial significación sistemática" (Benjamin, "El concepto de crítica", 24-25. Énfasis mío). Aquí aparece, desde 1918, lo que será su pensamiento llamémosle 'paradójico'; siempre radical, nunca consecuente. Como si esta inacababilidad del quehacer crítico fuera la dirección única para alcan-

correspondencia. Agradezco la referencia a José Ricardo Chaves y a Úrsula Marx, encargada de los Archivos Benjamin en Berlín.

${ }^{3}$ Cfr. Scholem y Adorno, The Correspondence of Walter Benjamin, 359. 
zar el "contenido de verdad" tal y como aparece expuesto en su lectura de las Afinidades electivas de Goethe; es decir, como si su carácter inacabable fuera justamente el principio de un pensamiento sistemático. ${ }^{4}$ Benjamin afirma que para "Schlegel y Novalis la infinitud de la reflexión no es primordialmente una infinitud del proceso, sino una infinitud de su conexión [...] entendían la infinitud de la reflexión como una colmada infinitud de la conexión: en ella todo debía conectar de modo infinitamente múltiple, sistemático" (Benjamin, " 'Las afinidades electivas' de Goethe”, 29. Énfasis mío).

¿En qué medida, podríamos preguntarnos, esta colmada infinitud de la conexión nos remite directamente al concepto benjaminiano de constelación $?^{5}$ ¿En qué sentido la propuesta de una crítica infinita conduce a Benjamin a pensar las obras

${ }^{4}$ No es mi intención aquí discutir el texto benjaminiano sobre Goethe, éste merecería por sí solo un ensayo aparte. Quede apuntado solamente que Benjamin plantea en su estudio sobre el poeta alemán una diferencia entre el comentario y la crítica. Cito: "La crítica busca el contenido de verdad de una obra de arte, y en cambio el comentario su contenido objetivo" (Benjamin, “'Las afinidades electivas' de Goethe”, 125). Y más adelante escribe: "el crítico debería comenzar por la lectura del comentario. Y de ahí surge de pronto un criterio inapreciable de su juicio: sólo ahora puede plantear la pregunta crítica fundamental acerca de si la apariencia del contenido de verdad se debe al contenido objetivo o a la vida del contenido objetivo, al contenido de verdad. Pues al separarse éstos en la obra, deciden sobre su inmortalidad [...] si, a modo de símil, se quiere ver la obra en crecimiento como una hoguera en llamas, el comentarista se halla ante ella como un químico, el crítico como un alquimista. Mientras que para el primero sólo la madera y la ceniza resultan objeto de su análisis, para el segundo únicamente la llama misma contiene un enigma: el de lo vivo. Así, el crítico pregunta por la verdad, cuya llama sigue ardiendo sobre los pesados leños de lo que ha sido y la liviana ceniza de lo vivido" (126. Énfasis mío). Cabría, en este sentido, asociar la idea del "umbral" con el símil de la "llama [que] sigue ardiendo", para intentar comprender la complejidad del quehacer crítico en la obra de Benjamin.

${ }^{5}$ El concepto de constelación aparece de manera sistemática a lo largo de la obra de Benjamin y se relaciona con la historia, con la escritura proustiana de la rememoración, entre otras. Cito sólo un fragmento del Libro de 
de su tiempo como una constelación de fragmentos? ${ }^{6}$ Sin duda alguna, el romanticismo temprano tuvo un influjo determinante en su pensamiento que toma, en sus propios términos, la idea de Schlegel de que "por muy elevadamente que se evaluara la validez de una obra crítica, ésta no puede ser algo concluyente" (53. Énfasis mío). Sin embargo, habría que hacerle justicia a Benjamin reconociendo que antes de elaborar su teoría sobre el romanticismo, en su precoz ensayo de 1916 sobre el lenguaje - "Sobre el lenguaje en general y sobre el lenguaje de los humanos"-, el autor ya planteaba una idea similar en relación con lo inconcluso de todo lenguaje. En aquel texto fundamental para comprender su teoría del lenguaje diseñaba con mano fina la imposibilidad del lenguaje mismo para entregársenos de manera total; su caída, incluso antes de ver completada la creación, en el momento en que se le otorga al hombre la facultad de nombrar a la naturaleza, había disuelto toda posibilidad de

los pasajes, que da cuenta de la complejidad benjaminiana para entender la historia. Ésta no sigue un transcurso lineal sino que enlaza el pasado con el tiempo "ahora". "No es que lo pasado arroje luz sobre lo presente, o lo presente sobre lo pasado, sino que imagen es aquello en donde lo que ha sido se une como un relámpago al ahora en una constelación. En otras palabras: imagen es la dialéctica en reposo. Pues mientras que la relación del presente con el presente es puramente temporal, continua, la de lo que ha sido con el ahora es dialéctica: no es un discurrir, sino una imagen en discontinuidad. - Sólo las imágenes dialécticas son auténticas imágenes (esto es, arcaicas), y el lugar donde se las encuentra es el lenguaje. Despertar-" (Benjamin, Libro de los pasajes, 464).

${ }^{6} \mathrm{El}$ concepto de fragmento es central en la obra de Benjamin; de hecho, su gran aspiración era hacer un libro de citas, de fragmentos, que hablaran por sí solos, "nada qué decir, sólo que mostrar". Y no obstante que su obra resulta en todo altamente compleja, encontramos varios de sus textos donde el autor privilegia lo fragmentario al desarrollo largo y explícito de muchas de sus ideas. Cfr. Dirección única, Parque Central y el mismo Libro de los pasajes. Como escribe Mayorga, "el tema del fragmento es la tensión entre la larga vida del mundo natural y la breve historia de la humanidad, comprimible en el ahora de un hombre" (Mayorga, Revolución conservadora, 108). 
reconstrucción de lo que él llamaba la "vasija rota". También su texto sobre la tarea del traductor retomaba el mismo impedimento: traducir significa tratar de recuperar los fragmentos disgregados de la "vasija rota", que no es ni más ni menos que el lenguaje puro, originario, anterior a todo lenguaje articulado en el que las cosas, la naturaleza y el hombre simplemente se comunicaban. Desde entonces, Benjamin pisaba el umbral de una reflexión abiertamente teológica o, si se quiere, dicho de manera más propia, mística, de la que hablaremos más adelante.

La idea benjaminiana del lenguaje caído, incapaz de dar cuenta de una verdad, de la historia y el arte, vuelve a aparecer en 1918 en su particular visión del espíritu romántico alemán. Si bien la crítica, al igual que el lenguaje, no tiene la posibilidad de entregarnos un "contenido de verdad absoluto" porque, en efecto, diría Benjamin, vivimos en un lenguaje caído, ésta se encuentra al menos obligada a darnos, muy a su pesar o a su incapacidad, "iluminaciones profanas" de la obra, acercamientos inconclusos que privilegien el fragmento, no en su carácter de elemento parcial de una estructura sino en la medida en que se trata de un sistema en sí mismo. Por ello, Benjamin cita al propio Schlegel: "todo fragmento es crítico" y hablar de "crítico y fragmentos sería tautológico" (52). En este sentido, el pensamiento benjaminiano se aventura en el análisis del fragmento para tener acceso a lo reflexivo y lo sistemático: "Pues un fragmento [...] es para él [Schlegel] como todo lo espiritual, un medio de la reflexión" (52, 22 y 206). Y de manera mucho más contundente, habría que escuchar a Novalis, en sus Estudios sobre Fichte, cuando dice: "El verdadero sistema filosófico tiene que unir libertad e infinitud; o, dicho de un modo sorprendente, tiene que poner en un sistema la falta de sistema" (apud Mendoza, El Ethos romántico, 58).

Ahora bien, la idea de lo asistemático/sistemático no es privilegio único de los románticos, el problema se presenta a su vez en el pensador ruso del dialogismo, Mijaíl Bajtín, su con- 
temporáneo. Benjamin también acude a Nietzsche para "arroparse" en esta nueva forma de hacer filosofía; sus aforismos, dirá nuestro autor, nada tienen de falta de rigor; muy por el contrario, y no obstante que el propio Nietzsche se considerara enemigo de los sistemáticos, "pensó plenamente su filosofía global y unitariamente según las ideas rectoras, y comenzó finalmente a escribir su sistema" (44). Sin embargo, un lugar especial se merece el pensamiento del filósofo ruso, quien nació sólo tres años después de Walter Benjamin, pero cuya obra, no obstante y a pesar de la distancia - nunca se conocieron, nunca se leyeron, nunca supo uno de la existencia del otro-- incursiona y explora el universo literario en una dirección similar, aunque sobre principios diferentes a los del pensador alemán. Dostoievski es para Bajtín, lo que Baudelaire o Kafka fueron para Benjamin, autores de lo inconcluso, de lo inacabable y del diálogo infinito; los personajes de estos escritores son los "guardianes del umbral” del que Benjamin habla en relación con la crítica. La polifonía bajtiniana da cuenta del estado del hombre en el mundo, por ello la obra de Dostoievski, desde su particular perspectiva, da a Bajtín la posibilidad de explorar las diferentes voces que encarnan sus personajes; como él mismo escribe al referirse a la autoridad del crítico formalista:

Shklovski toca el complejo problema de la fundamental inconclusividad de la novela polifónica. En efecto, en las novelas de Dostoievski encontramos un conflicto particular entre la inconclusión interna de los héroes y del diálogo y un acabado externo (en la mayoría de los casos, de tipo argumental) de cada novela en sí (Bajtín, Problemas de la poética de Dostoievski, 66. Énfasis mío).

En este sentido, Bajtín toca aún más las cuerdas sensibles de la figura benjaminiana del "narrador" que, sabemos, lucha contra

${ }^{7}$ Cfr. "El narrador", en Walter Benjamin, Para una crítica de la violencia y otros ensayos. En este ensayo, escrito en 1936, Benjamin hace una 
la muerte y para ello propone justamente la continuidad de la experiencia del uno en boca de un otro. Bajtín plantea una idea similar respecto de los muertos de Dostoievski:

Dostoievski no representaría las muertes de sus héroes, sino las crisis y las rupturas en sus vidas, es decir, dibujaría sus vidas en el umbral. Sus personajes permanecerían interiormente inconclusos (puesto que la autoconciencia no puede ser concluida desde el interior). Sólo así se presentaría la modalidad polifónica del relato (111. Énfasis mío).

De la misma manera, Benjamin rescatará más adelante la figura retórica de la alegoría en su texto sobre el Trauerspiel —redactado entre 1917-1925, publicado en 1927_, , confrontándola con el símbolo romántico, en el sentido en que la primera representa un tipo de experiencia, definida en términos de aprehensión del mundo "como algo no permanente, como un desvanecerse del ser: un sentido de transitoriedad, un presentimiento de la mortalidad o una convicción de que, como en Dickinson, 'este mundo no es una conclusión'” (Cowan, "Walter Benjamin's Theory of Allegory", 110). En igual medida, para Bajtín y su visión de Dostoievski, "no existen objetos petrificados, muertos, conclusos, afónicos, que hubiesen dicho ya su última palabra" (Bajtín, Problemas, 270).

Si me he permitido dar un salto geográfico (Alemania-Unión Soviética), mas no temporal, es justamente porque estos dos pensadores (Benjamin y Bajtín) se encuentran en una dimensión reflexiva singular; para ambos filosofía y literatura van de la mano y encuentran su objetivo en la tarea de la crítica. La reflexión, dirá Benjamin, "es el estilo del pensamiento" (Benja-

severa crítica a la primera guerra mundial que provocó la desaparición de la figura del narrador, "guardián de la memoria y la justicia", ya que la gente que volvía de las trincheras ya no tenía ninguna experiencia que contar.

${ }^{8} \mathrm{Me}$ refiero a su libro El origen del 'Trauerspiel' alemán. 
min, "El concepto de crítica", 22. Énfasis mío), pero más aún, dirá el filósofo alemán: "Está claro que para los románticos la crítica es mucho menos el enjuiciamiento de una obra que el método de su consumación" (70. Énfasis mío). Y, en este punto, podríamos aludir a la máxima benjaminiana del pensamiento como intervención, como posibilidad de producir nuevos conceptos e imágenes que vengan a "integrar" las obras, a insertarlas en constelaciones más amplias, podríamos decir incluso, a completarlas. El concepto de "obra abierta" de Umberto Eco bien podría entenderse en estos términos y habría, quizás, que explorar más a fondo esta idea de intervención en la obra de un pensador de la estatura de Jacques Derrida, quien hace suya la noción, en términos generales, de la deconstrucción como una forma de intervención en el texto. Pero dejemos la interrogante en suspenso; en última instancia, ¿acaso no decía el propio Benjamin que las citas eran "salteadores de caminos" que irrumpían en el trayecto de los paseantes? Y él mismo, ¿no fue acaso uno entre los mejores paseantes?

Volvamos a Benjamin y a su idea de crítica como guardián del umbral. La pregunta que se impone irremediablemente es ¿umbral de qué? En el relato de Kafka, "Ante la ley”, 9 sabemos que el guardián trata de resguardar esa "Ley" con mayúsculas a la que Kafka se ve fatalmente sometido en todos y cada uno de sus relatos. Pero, ¿a quién protege, a quién cuida ese crítico desde la escritura? ¿Acaso se trata de impedir el acceso al "contenido de verdad" de toda crítica, o sólo se trata de permitir a algunos "privilegiados" el acceso a ésta? No podríamos continuar hablando de la crítica romántica y su percepción benjaminiana sin asumir que existe en todo su pensamiento una visión

${ }^{9}$ En este caso, corro el riesgo de imaginar su concepto de umbral en relación con la obra de Kafka, aceptando que no hay pruebas absolutas que lo certifiquen, además de la fascinación de Benjamin por este autor y, en particular, por su relato "Ante la ley". 
mística o, si se quiere, metafísica. Mucho se ha escrito sobre la influencia que tuvo la mística judía en Benjamin, a través de su profunda amistad con Gershom Scholem; algunos, marxistas ortodoxos, montan en cólera cuando se sugiere el tema; otros, como el propio Scholem, acusan a aquellos que desviaron a su entrañable amigo de su vocación originaria, es decir, la teológica. Otros más, como Adorno y Horkheimer, nunca se sintieron del todo a gusto con las paradojas de un Benjamin que, al tiempo que hablaba del materialismo histórico, lo asociaba, en la figura del jorobadito, con la teología. De hecho, aun después de su muerte, no fue sino Hannah Arendt la que recuperó su escrito póstumo, las Tesis sobre la historia, frente al desapego de Adorno ante un texto que prefiguraba una dialéctica no lo suficientemente dialéctica, así como un materialismo apoyado sin sutilezas sobre la teología. Incluso, para cerrar ese esbozo de la recepción de la obra benjaminiana, basta escuchar al "amigo" Brecht blasfemar contra el texto de Benjamin sobre Kafka diciendo que ese artículo "fomentaba el fascismo judío", que se trataba de "pura mística, a pesar de la postura antimística". Y con ironía exclama: “¿Es así como se adapta la concepción materialista de la historia!" (Brecht, Journal de travail, 15). ¿Me pregunto si es posible ahora, en tiempos tan oscuros como los que vivió el propio Benjamin, pensar en una constelación crítica que involucre elementos místicos sin hacer palidecer la irradiación del pensamiento benjaminiano ${ }^{10}$

${ }^{10}$ El tema del misticismo en la obra de Benjamin es vastísimo, no sólo ante la posibilidad de considerarlo como una parte articulada de su pensamiento sino ante el origen de sus influencias. Gershom Scholem se adjudicó su propia influencia como definitiva en la obra del pensador alemán y ciertamente tiene razón si se piensa en algunos textos en particular. Sin embargo, habría que subrayar que ya en los escritos tempranos de Walter Benjamin, como el del lenguaje de 1916, el filósofo hace referencia a un misticismo, que si nos apegamos a las fechas en que Scholem y Benjamin estuvieron en contacto, nos remitiría más bien a la tradición mística alemana desde el Maestro Eckhart (1250-1312) hasta Jakob Böhme (siglo XVII). De ahí que 
Desafortunadamente, pocos son aquellos que logran asumir la gran paradoja que implica comprender a Benjamin desde dentro, desde ese lugar que él mismo se adjudica, como guardián de un umbral, de quien desconocemos si impedirá o cederá el paso a los que tengan la fuerza y la osadía de acariciar el absoluto, sea el materialismo histórico, sea el misticismo romántico o judío. Frente a un lenguaje del que hemos sido despojados desde el inicio de los tiempos, cuyo cuerpo se aleja de nosotros en lo que para Benjamin fue la peor de las caídas - tener que comunicarnos "a través de" y no "en" el lenguaje" —, hasta la crítica que sabe que "El sujeto de la reflexión es en el fondo el producto artístico mismo, y que el experimento consiste [...] en el despliegue, en un producto de la reflexión [...] del espíritu" ("El concepto de crítica", 67. Énfasis mío), Benjamin no abandona y nunca, ni en el más 'político' de sus textos, las Tesis, abandonará su espectro místico.

No es éste el espacio para discutir a fondo si la mística benjaminiana tiene su fundamento en el legado romántico alemán o si éste, como lo quieren Scholem, gran estudioso del misticismo hebreo, y sus defensores, tuvo de manera absoluta una cuna judía. Ambas propuestas me parecen ciertamente sólidas, aunque pueda inclinarme, sobre todo en algunos textos donde el mismo Benjamin hace alusión a la cábala, a una influencia directamente judía a través de la mirada de Gershom Scholem. Lo que resulta enigmático y extremadamente delicado es acercarse a esta oscura constelación donde el materialismo histórico y la mística conviven como la naturaleza y el hombre antes de su caída del paraíso y, más concretamente, antes de la caída del lenguaje mismo, donde, me atrevería a apostar, Benjamin

desde su estudio sobre el Romanticismo alemán, Benjamin estuviera empapado de esa tradición, y no necesariamente de la tradición judía.

${ }^{11}$ Cfr. Benjamin, "Sobre el lenguaje en general y sobre el lenguaje de los humanos". 
podía observarlos conviviendo simplemente. Parecería que la paradoja en Benjamin está del otro lado del umbral, es decir, del otro lado de un racionalismo, de una lógica certera y de un materialismo mecanicista. De igual manera, para el filósofo alemán, el lenguaje y la crítica comparten ese duelo originario del que podrán sanar sólo aquellos que asuman como punto de partida la pérdida y el abismo en que ambos se encuentran.

Desde este panorama habrá que entender la obra benjaminiana y su esfuerzo por custodiar ese umbral que augura la "felicidad" como un intento por acercarse a ese "contenido de verdad", aunque se nos esté negada la admisión a menos que no sea en un destello, "en un instante de peligro" o en una "iluminación profana". Si bien este planteamiento nos puede conducir por la filosofía kantiana, ${ }^{12}$ en este momento quisiera apuntar de manera más directa a ese jorobadito que Benjamin, en sus escritos de juventud, no dudó en llamar Dios. Si consideráramos su estudio sobre las Afinidades electivas de Goethe como el paradigma de su concepción crítica, donde el "contenido de verdad", objetivo definitorio de toda crítica (literaria o filosófica) que se reconozca como tal, es a fin de cuentas prácticamente inalcanzable, ¿qué nos queda para entender a fondo la posibilidad misma de la crítica? ¿Estamos condenados a quedarnos en el nivel del comentario? Benjamin, en su segunda versión definitiva del texto Agesilaus Santader (Ibiza, 13 de agosto de 1933), enigmático por decir lo menos, a pesar de que Scholem tenga siempre la respuesta adecuada, se define frente a su ángel como de espíritu saturnino ("Aprovechando la circunstancia de que vine al mundo bajo Saturno — el astro de la revolución lentísima, el planeta de las digresiones y de las demoras - "). ${ }^{13}$ Quizás sea en esa

${ }^{12}$ Aquí sería importante recordar que, en un principio, el proyecto sobre el romanticismo alemán llevaba el nombre de "La tarea infinita en Kant". Cfr. W. Benjamin, Le concept de critique esthétique dans le romantisme allemand.

${ }^{13}$ En Scholem, Walter Benjamin e il suo angelo, 23. Énfasis mío. 
revolución lentísima, en la sutil demora y en la paciencia que lo caracteriza, como podamos, a la larga, encontrar ese oscuro camino por donde transitó Benjamin. No habría que olvidar la máxima kafkiana que considera la impaciencia como el mayor de los pecados. No sé si Benjamin pueda pensarse, desde la perspectiva de Kafka, como el guardián del umbral, o como el campesino que espera paciente ante las puertas de la ley, sino, ni más ni menos, como el umbral mismo, como "la llama ardiente", donde filosofía, crítica, mística y materialismo histórico encuentran finalmente un lugar compartido por "habitar".

\section{REFERENCIAS}

Bajtín, M. Mijaíl, Problemas de la poética de Dostoievski, trad. Tatiana Bubnova, México, Fondo de Cultura Económica, 2003.

Benjamin, Walter, Para una crítica de la violencia y otros ensayos, Madrid, Taurus, 1988.

—_, "El París del Segundo Imperio en Baudelaire", en Iluminaciones II. Poesía y capitalismo, trad. Jesús Aguirre, Madrid, Taurus, 1999, 21-120.

_- "Sobre el lenguaje en general y sobre el lenguaje de los humanos", en Iluminaciones IV. Para una crítica de la violencia y otros ensayos, trad. Roberto Blatt, Madrid, Taurus, 1999, 59-73.

__, Tesis sobre la historia y otros fragmentos, trad. Bolívar Echeverría, México, Contrahistorias, 2005.

—_, Libro de los pasajes, Rolf Tiedemann (ed.), Madrid, Akal, 2005. ,"El concepto de crítica de arte en el Romanticismo alemán", en Obras, Libro I/vol. 1, Madrid, Abada, 2006.

__, “Las afinidades electivas'de Goethe”, en Obras, Libro I/vol. 1, Madrid, Abada, 2006.

, "Presentación de la revista 'Angelus Novus", en Obras, Libro II/vol. 1, Madrid, Abada, 2007.

$\ldots$ Le concept de critique esthétique dans le romantisme allemand, Euvres et inédits, édition critique intégrale, tomo 3, París, Fayard, 2009. 
BRECHT, Bertolt, Journal de travail 1938-1955, París, L’Arge, 1976.

CowAn, Bainard, "Walter Benjamin's Theory of Allegory", New German Critique, 22, invierno 1981, 109-122.

Mayorga, Juan, Revolución conservadora y conservación revolucionaria. Política y Memoria en Walter Benjamin, México, Anthropos-UAM, 2003.

Mendoza, Emiliano, El Ethos romántico. Fundamentos de la poética del primer Romanticismo filosófico, Morelia Michoacán, junio 2009 [Tesis].

Scholem, Gershom, Walter Benjamin e il suo angelo, trad. M.T. Mandalari, Adelphi, Milán, 1978.

Scholem, Gershom y Theodoro W. Adorno (ed. y notas), The Correspondence of Walter Benjamin, 1910-1940, Chicago, The University Press of Chicago, 1994. 